\title{
Genomic imbalances detected by comparative genomic hybridization are prognostic markers in invasive ductal breast carcinomas
}

\author{
I Zudaire, M D Odero, C Caballero, ${ }^{1}$ C Valenti, ${ }^{1} \mathrm{~J}$ M Martínez-Penuela, ${ }^{1} \mathrm{~J}$ Isola ${ }^{2}$ \& M J Calasanz \\ Department of Genetics, University of Navarra and ${ }^{1}$ Department of Pathology, Hospital of Navarra, Pamplona, Spain, and \\ ${ }^{2}$ Laboratory of Cancer Genetics, Institute of Medical Technology, University and University Hospital, Tampere, Finland
}

Date of submission 28 November 2001

Accepted for publication 22 February 2002

Zudaire I, Odero M D, Caballero C, Valenti C, Martínez-Penuela J M, Isola J \& Calasanz M J

(2002) Histopathology 40, 547-555

\section{Genomic imbalances detected by comparative genomic hybridization are prognostic markers in invasive ductal breast carcinomas}

Aims: The aim of this work is the study of the prognostic significance of the chromosomal aberrations described in a series of invasive ductal breast carcinomas.

Methods and results: We analysed by comparative genomic hybridization a group of 70 formalin-fixed paraffin-embedded invasive ductal breast carcinomas. Aberrations showed a frequency similar to previous studies using frozen tumours. Interestingly, we identified gains involving 6q16-q24 more frequently than in other series. We analysed the association among the chromosomal imbalances, 11 histopathological factors, relapse rate and overall survival of patients. Associations showed $16 \mathrm{q}$ losses as a potential marker of good prognosis, as they were more frequent in node-negative
$(P=0.025)$ and in oestrogen-positive tumours $(P<$ 0.001 ). Furthermore, $100 \%$ of bcl-2+ tumours presented this aberration compared with $29.3 \%$ in bcl-2$(P=0.014) .1 \mathrm{q}, 11 \mathrm{q}, 17 \mathrm{q}$ and $20 \mathrm{q}$ gains were associated with poor prognosis: $95 \%$ of cases with 1q gains were bigger than $20 \mathrm{~mm}(P=0.041)$. Tumours with $1 \mathrm{q}$ and $11 \mathrm{q}$ gains showed a higher relapse rate $(P=0.063 ; P=0.066)$. Within the good prognosis group of lymph node-negative patients, $17 \mathrm{q}$ and $20 \mathrm{q}$ gains identify a subgroup with increased relapse rate $(P=0.039)$.

Conclusions: Chromosomal imbalances, together with histopathological factors, may help to predict outcome in breast cancer patients.

Keywords: CGH, prognostic factors, invasive ductal breast carcinomas, 6q gains, 16q losses

\section{Introduction}

Breast cancer is the most frequent type of cancer among women in western countries. ${ }^{1}$ Because of its incidence and complexity, enormous efforts have been made to increase knowledge about breast cancer biology and to develop new therapeutic strategies. ${ }^{2}$ Many new prognostic factors have been suggested, but the prognostic value of a wide number of them is still not confirmed. A recent review of prognostic factors used in breast cancer has considered tumour size, nodal

\footnotetext{
Address for correspondence: Isabel Zudaire Ripa, Department of Genetics, University of Navarra, C/Irunlarrea s/n, 31008 Pamplona, Spain. e-mail: izudaire@unav.es
}

status, micrometastasis, histological grade and type, mitotic figure count and hormone receptor status as the only factors with prognostic value and use in clinical patient management. ${ }^{3}$

Genetic studies have contributed to increase the knowledge of this disease. One of the most useful genetic techniques to study breast cancer has been comparative genomic hybridization (CGH). CGH allows detection of chromosomal imbalances without the need for tumour metaphases and with the possibility of using any source of tissue (fresh, frozen or paraffin-embedded specimens). In breast cancer, the main chromosomal imbalances detected have been gains on $8 \mathrm{q}, 1 \mathrm{q}, 11 \mathrm{q}$, $17 \mathrm{q}$ and $20 \mathrm{q}$ and losses on 16q, 8p, 13q, 17p and $11 \mathrm{q} 23.1 \mathrm{q}$ gains and $16 \mathrm{q}$ losses have been reported to 
be involved in early steps in cancer progression; 8q, $11 \mathrm{q}, 17 \mathrm{q}$ and $20 \mathrm{q}$ gains and 13q losses have been associated with aggressive phenotypes and have allowed the characterization of new genes such as AIB1 (20q13). ${ }^{4-6}$

Most of the CGH publications have focused on the description of chromosomal imbalances, but several studies have also reported the associations between chromosomal imbalances and clinicopathological prognostic factors in retrospective analysis, using paraffinembedded and frozen tissues. ${ }^{5-7}$ In breast cancer, no more than three pathological parameters have been considered. The pathological factor more frequently studied has been the histological grade. ${ }^{8,9}$ Oestrogen receptor expression (ER), ${ }^{10}$ the value of the mean nuclear area, the mitotic index and the apoptotic index ${ }^{6,11}$ have also been considered. Tirkkonnen et al. studied 55 unselected breast carcinomas where associations with tumour size, nodal status, grade, ER and progesterone receptor (PR) expression, DNA index and S-phase fraction were established. ${ }^{5}$ They found gains of $8 \mathrm{q}$ correlated with DNA index and high S-phase fraction, as well as the association between $\mathrm{Xq}$ loss and oestrogen receptor negativity.

We present the analysis of a homogeneous series of 70 invasive ductal breast carcinomas by CGH. In order to find genetic aberrations that may be used as prognostic markers, we associated the chromosomal imbalances found with 11 histopathological parameters routinely determined in clinical management, the overall survival and the relapse rate.

\section{Materials and methods}

\section{PATIENTS}

We selected 70 patients diagnosed with invasive ductal breast carcinoma at the Hospital of Navarra between 1991 and 1994. Pathological characterization of the samples was done according to the European Commission Group on Breast Screening Pathology (ECGBP). ${ }^{12}$ The mean age of the patients was 62.5 years (range 33-95 years). The mean follow-up time was 64 months (range 6-103 months). Diseasefree survival and the presence of local, regional and/or distant metastases were also noted. The 2-year overall survival of the series was $87 \%(\mathrm{SD}=4.5 \%)$ and $75.9 \%$ within 5 years $(\mathrm{SD}=5.8 \%)$. The 2-year relapse rate was $14.6 \% \quad(\mathrm{SD}=5.1 \%)$ and $29.2 \% \quad(\mathrm{SD}=6.5 \%)$ within 5 years.

\section{PATHOLOGICAL FACTORS}

From each sample tumour size, histological grade, axillary lymph node status and Nottingham Prognostic Index were evaluated. Immunohistochemical study of ER and PR), p53 and Ki67 were made using the Ventana $^{\text {TM }}$ Enhanced DAB Detection Kit. bcl-2 and ErbB-2 expression were studied by the Super Sensitive Immunodetection System (Biogenex). More details about immunohistochemistry methodology are listed in Table 1. DNA ploidy was analysed by cytometry after Feulgen staining. In all cases, positive and negative controls were used. Immunohistochemistry results were scored semiquantitatively in four grades, considering levels $0,1,2$, and 3 according to the number of positive cells and the intensity of the staining. In order to facilitate the statistical analysis we classified the immunohistochemistry results in positive or negative groups. Table 2 summarizes the pathological features of the samples analysed.

\section{COMPARATIVE GENOMIC HYBRIDIZATION}

Genomic DNA was isolated from archival paraffin block samples. Prior to DNA extraction, we selected in each sample the most representative tumour region according to the adjacent haematoxylin-eosin-stained

Table 1. Immunohistochemical stains

\begin{tabular}{llll}
\hline Antibody/antigen & Source & Dilution & Antigen retrieval \\
\hline Oestrogen receptor & ATOM-Ventana & Prediluted & 10x antigen retrieval Citra solution pressure cooker, 4 min \\
\hline Progesterone receptor & ATOM-Ventana & Prediluted & $10 x$ antigen retrieval Citra solution pressure cooker, 4 min \\
\hline p53 & ATOM-Ventana & Prediluted & $10 x$ antigen retrieval Citra solution pressure cooker, 4 min \\
\hline erbB-2 & BioGenex & Prediluted & 10x antigen retrieval Citra solution pressure cooker, 4 min \\
\hline bcl-2 & BioGenex & $1: 100$ & $10 x$ antigen retrieval Citra solution pressure cooker, 4 min \\
\hline Ki67 & Dako & $1: 50$ & $10 x$ antigen retrieval Citra solution pressure cooker, 4 min \\
\hline
\end{tabular}


Table 2. Pathological features of the 57 invasive ductal breast carcinoma samples analysed by $\mathrm{CGH}$ in this study

\begin{tabular}{|c|c|c|}
\hline Pathological factors & $n$ & $\%$ \\
\hline \multicolumn{3}{|l|}{ Tumour size } \\
\hline$<20 \mathrm{~mm}$ & 10 & 17.5 \\
\hline$\geq 20 \mathrm{~mm}$ & 47 & 82.5 \\
\hline \multicolumn{3}{|l|}{ Histological grade } \\
\hline 1 & 3 & 5.3 \\
\hline II & 34 & 59.6 \\
\hline III & 20 & 35.1 \\
\hline \multicolumn{3}{|l|}{ Node status } \\
\hline No nodes involved & 26 & 45.6 \\
\hline $1-3$ nodes involved & 16 & 28.1 \\
\hline 4 nodes involved & 13 & 22.8 \\
\hline No data & 2 & 3.5 \\
\hline \multicolumn{3}{|l|}{ Oestrogen receptors } \\
\hline Negative & 42 & 73.6 \\
\hline Positive & 15 & 26.4 \\
\hline \multicolumn{3}{|l|}{ Progesterone receptors } \\
\hline Negative & 37 & 65 \\
\hline Positive & 20 & 35 \\
\hline \multicolumn{3}{|l|}{ p53 } \\
\hline Negative & 31 & 54.4 \\
\hline Positive & 26 & 45.6 \\
\hline \multicolumn{3}{|l|}{ erbB-2 } \\
\hline Negative & 31 & 54.4 \\
\hline Positive & 26 & 45.6 \\
\hline \multicolumn{3}{|l|}{ bcl-2 } \\
\hline Negative & 16 & 28 \\
\hline Positive & 41 & 72 \\
\hline \multicolumn{3}{|l|}{ Ki67 } \\
\hline Negative & 0 & 0 \\
\hline Positive & 57 & 100 \\
\hline \multicolumn{3}{|l|}{ Ploidy } \\
\hline Diploid & 15 & 26.3 \\
\hline Aneuploid & 41 & 71.9 \\
\hline No data & 1 & 1.8 \\
\hline \multicolumn{3}{|c|}{ Nottingham Prognostic Index } \\
\hline Good prognosis & 10 & 17.5 \\
\hline Moderate prognosis & 24 & 42.1 \\
\hline Poor prognosis & 21 & 36.8 \\
\hline No data & 2 & 3.5 \\
\hline
\end{tabular}

section. In order to obtain a good quality of DNA, extraction was performed with a protocol slightly modified from Isola et al. ${ }^{13}$ Briefly, multiple thin sections from tissue were digested with proteinase $\mathrm{K}$ at $55^{\circ} \mathrm{C}$ during $3-5$ days. A commercial DNA purification kit (QIAamp Tissue Kit; Quiagen, Hilden, Germany) was used to purify DNA. Direct DNA labelling was performed using Vysis nick translation kit (Vysis $\mathrm{GmbH}$, Stuttgart, Germany). Digestion time and enzyme concentration were adjusted for each sample. In order to avoid an excessive DNA fragmentation we reduced DNase and nick translation reaction time to 20 min. The labelling of this DNA was improved by increasing the DNA polymerase I concentration. In six cases, preamplification of the DNA using degenerate oligonucleotide-primed PCR methodology (DOP-PCR) was necessary. ${ }^{14}$

Because of the high DNA fragmentation, spectrophotometry usually overestimates DNA concentration from paraffin samples. In order to obtain confirmation we added equal concentrations of both DNAs; sexmismatched experiments were used. For each case, between 8 and 10 metaphases were analysed. Numerical analysis of DNA imbalances was performed using fixed thresholds: 0.8 for losses and 1.2 for gains.

\section{STATISTICAL ANALYSIS}

Statistical analysis was performed with SPSS software (Windows v. 9.0). Differences in the average of copy number aberrations among groups characterized by histopathological factors were analysed with Student's $t$-test, one way analysis of variance or the MannWhitney U-test, and Kruskall-Wallis test depending on the results of Kolmogorov-Smirnov normality test.

The differences in the frequency of the most common gains and losses (those present in $>15 \%$ of cases) among histopathological groups were analysed by the $\chi^{2}$ contingency test.

The relationship between histopathological factors and chromosomal aberrations with the overall survival and the relapse rate was analysed by the Kaplan-Meier method. The association of the copy number aberrations to prognosis was analysed by the regression Cox test.

Values of $P \leq 0.05$ were considered to be statistically significant and $0.05<P \leq 0.1$ were considered to be nearly significant. The size of the different subgroups and the low number of events prevented multivariate analysis.

\section{Results}

Technically successful results were obtained in 57 out of 70 tumours $(81.4 \%)$. CGH detected genetic aberrations in 55/57 tumours (96\%). The mean number of copy number aberrations was 5.8 per tumour $(\mathrm{SD}=$ 0.45 , range $0-15)$. The number of gains was 3.6 $(\mathrm{SD}=0.28$, range $0-9)$ and that of losses 2.2 
$(\mathrm{SD}=0.27$, range $0-8)$. A summary of all chromosomal aberrations detected is shown in Figure 1. Chromosomal changes affected all chromosomes except chromosome 21 . The most frequent gains were on $8 \mathrm{q}$ (63.1\%), 17q (45.6\%), 1q (38.6\%), 20q (26.3\%), 11q $(21 \%)$ and $6 \mathrm{q}(17.5 \%)$. The most frequent losses affected at $16 \mathrm{q}(21 \%), \mathrm{Xp}$ and $\mathrm{Xq}(19.3 \%), 13 \mathrm{q}$ (17.5\%), 11q (15.7\%) and 8p (15.7\%).

It was common that the abnormalities affected entire chromosomes or chromosomal arms. However, subregional imbalances were detected in $11 \mathrm{q}$ (losses at 11q21-qter), 6q (gains at 6q16-q24, 6q16-q22, 6q22$\mathrm{q} 24$ ) and $14 \mathrm{q}$ (gains at 14q12-q22, 14q11-q24.2, 14q32, 14q14-q24, 14q11-q21). In 11 samples, we found aberrations limited at one band as gains on 1p21, 7q11, 11q13 and 12q15.

We detected slight differences in the average of copy number aberrations between histopathological groups: the average number of gains was higher in tumours $>20 \mathrm{~mm}$ relative to those of small size (3.9 versus 2.5; $P=0.058)$, and in tumours with p53 accumulation $(4.2$ versus $3.2 ; P=0.070)$. Samples positive for PR expression showed twice as many losses as PR-negative samples $(P=0.083)$. No associations were found between either copy number aberration and survival or copy number aberration and relapse rate.

We compared the aberrations present in $>15 \%$ of cases with 11 pathological factors. We first confirmed the prognostic value of the histopathological factors: only the size, the node status and the Nottingham Prognostic Index showed significant association with prognosis (Table 3). Chromosomal aberrations found to be significantly associated with pathological features are summarized in Table 4. Of tumours with 1q gains, $95 \%$ were $>20 \mathrm{~mm}(P=0.041)$. Of samples with $6 \mathrm{q}$

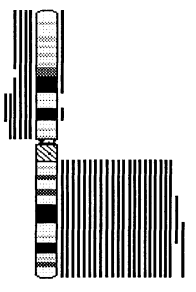

1

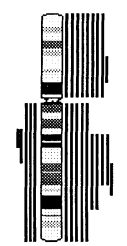

6

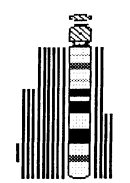

13

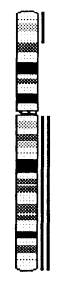

2

7

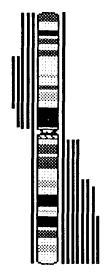

3

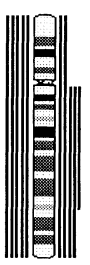

4

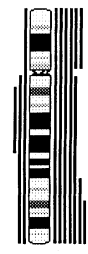

5

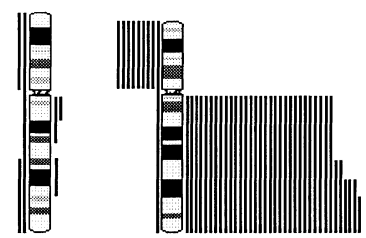

8

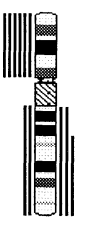

9

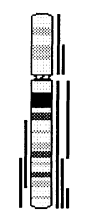

10

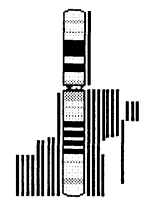

11

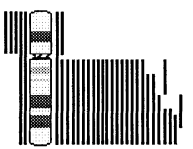

17

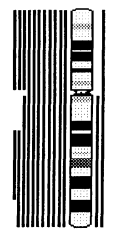

$\mathrm{X}$

Figure 1. Summary of the genetic imbalances detected in 57 invasive ductal carcinomas of the breast. The vertical lines on the right of the chromosome ideograms represent gains and the vertical lines on the left represent losses. 
Table 3. Associations between the pathological factors studied, overall survival and relapse rate

\begin{tabular}{lll}
\hline & $\begin{array}{l}\text { Overall survival } \\
P\end{array}$ & $\begin{array}{l}\text { Relapse rate } \\
P\end{array}$ \\
\hline Size & 0.052 & 0.051 \\
\hline Grade & 0.553 & 0.561 \\
\hline Node status & 0.003 & 0.001 \\
\hline Oestrogen receptor & 0.251 & 0.302 \\
\hline Progesterone receptor & 0.185 & 0.761 \\
\hline p53 & 0.792 & 0.463 \\
\hline erbB-2 & 0.725 & 0.145 \\
\hline bcl-2 & 0.137 & 0.807 \\
\hline Ki67 & 0.407 & 0.431 \\
\hline Ploidy & 0.286 & 0.272 \\
\hline Nottingham Prognostic & 0.032 & 0.069 \\
\hline Index & & \\
\hline
\end{tabular}

gains, $80 \%$ showed p53 accumulation $(P=0.016)$. $16 \mathrm{q}$ losses were more frequent in node-negative tumours $(P=0.025), 46.7 \%$ of samples positive for ER also showed 16q losses $(P<0.001)$ and $100 \%$ of tumours with this aberration showed a positive bcl-2 over-expression $(P=0.014)$. $8 q$ gains were more frequent in tumours classified within the poor prognostic group relative to those of the good prognostic group, according to the Nottingham Prognostic Index (81\% versus $30 \%, P=0.022$ ).

Kaplan-Meier analysis revealed a 5-year relapse rate of $41.3 \%$ for cases with gains on $1 \mathrm{q}$ and a rate of $18.5 \%$ for cases without $1 \mathrm{q}$ gain $(P=0.063)$. Patients with $11 \mathrm{q}$ gains showed a relapse of $50 \%$ compared with $23.7 \%$ in tumours without this imbalance $(P=0.066)$. Considering node-negative patients only, gains on $17 \mathrm{q}$ and $20 \mathrm{q}$ were significantly associated with early relapse $(P=0.039)$ (Figure 2$)$.

\section{Discussion}

Cytogenetic retrospective analyses are limited to the use of formalin-fixed and paraffin-embedded samples. The quality of the CGH analysis depends largely on the quality of tumour DNA. Especially when working with paraffin-embedded samples, high DNA fragmentation and poor labelling efficiency reduce the sensitivity of detection of chromosomal imbalances. ${ }^{13}$ In our study, we achieved a good quality labelling by reducing the concentration of DNase and the digestion time, and increasing concentration of the DNA polymerase I. According to the literature, $\mathrm{CGH}$ success rates are between $70 \%$ and $90 \%{ }^{15}$ When paraffin-embedded tissues are used, lower rates are expected. In our series, with the technical modifications described, we obtained a high success rate of $81.4 \%$.

Genetic changes identified in this series are similar to those described in other breast cancer CGH studies

Table 4. Significant associations between recurrent chromosomal imbalances and pathological factors

\begin{tabular}{lll}
\hline & Chromosomal imbalances & $P$ \\
\hline $\begin{array}{l}\text { Features of good prognosis } \\
\text { Node-negative tumours }\end{array}$ & Losses on $16 \mathrm{q}$ and $11 \mathrm{q}$ & 0.025 and 0.040 \\
\hline $\begin{array}{l}\text { Oestrogen receptor-positive } \\
\text { bcl-2-positive }\end{array}$ & Losses on $16 \mathrm{q}$ & 0.001 \\
\hline p53-negative & Losses on $16 \mathrm{q}$ & 0.014 \\
\hline $\begin{array}{l}\text { Progesterone receptor-positive } \\
\text { Features of poor prognosis }\end{array}$ & Losses on $11 \mathrm{q}$ & 0.021 \\
\hline $\begin{array}{l}\text { Tumours }>20 \text { mm } \\
\text { p53-positive }\end{array}$ & Losses on $\mathrm{Xq}$ & 0.021 \\
\hline Aneuploid tumours & Gains on $1 \mathrm{q}$ & 0.041 \\
\hline High Nottingham Prognostic Index & Gains on $6 \mathrm{q}$ & 0.016 \\
\hline
\end{tabular}



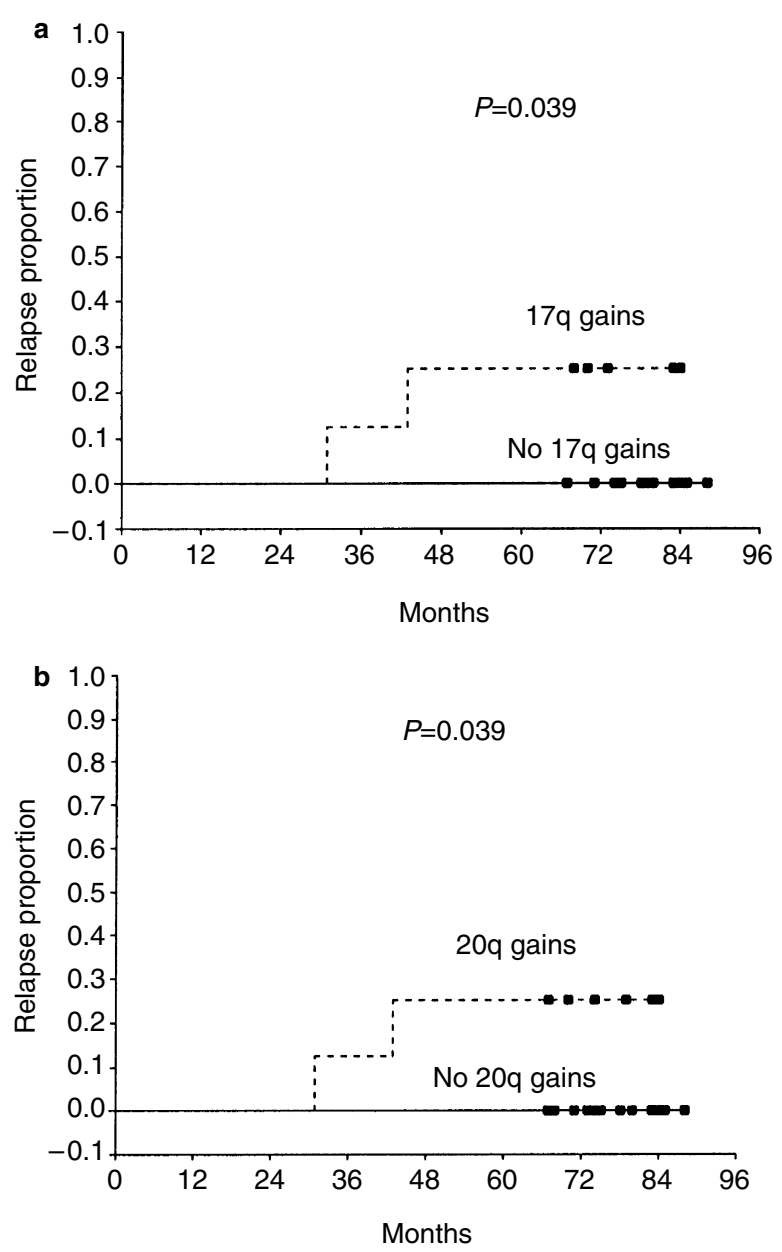

Figure 2. Relapse rate according to (a) 17q gains, and (b) 20q gains.

using mostly frozen tumours $5,8,10,11,15,16$ (Table 5). The different frequencies found between these previous publications and our series for 1q gains and $8 p$ losses could be due to a slightly lower sensitivity of CGH from paraffin samples and/or the presence of normal DNA in tumour samples. Gains on 8q, 1q, 17q, 20q and 11q and losses on 16q, Xq, 13q, 11q and 8p were the most frequent imbalances.

Interestingly, we found gains on $6 \mathrm{q}$ more frequently than in other series (Table 5). In these publications losses on $6 \mathrm{q}$ were always more frequent than gains. $^{5,7,8,10,11,15-17}$ Only Loveday et al. ${ }^{17}$ showed results similar to ours, with $6 \mathrm{q}$ gains more frequent than $6 \mathrm{q}$ losses. In our series, gains were limited to bands 6q16-q24, the minimal region involved being limited to 6q22-q23. Hermsen et al. ${ }^{11}$ and Kuukasjarvi et al. ${ }^{18}$ showed gains affecting the same bands, more frequent in aneuploid and bad prognosis tumours. Confirming our results, a recent allelotyping analysis of Rodriguez et al. ${ }^{19}$ showed that the $6 \mathrm{q} 21-\mathrm{q} 22$ region is most commonly involved in gains, whereas 6q13-q14 and 6q25-q27 are frequently lost. Bands 6q22-q23 harbour the $c-M Y B$ gene, and c-Myb expression has been associated with oestrogen stimulation and the presence of ER in breast cancer. This gene is amplified in this neoplasia more frequently in tumours with BRCA1 mutations than in sporadic tumours. ${ }^{20}$ In this regard, $20 \%$ of our cases with 6q gains showed a previous familiar history of breast cancer, although BRCA1 mutations have not been analysed. FISH studies analysing $M Y B$ amplification and other target genes in 6q22-q24 are in progress.

A rarely described gain on 14q11-q24 was detected in our study (minimal region involved 14q13-q21). The BRF1 gene has been described to be amplified in this region (14q22-q24) in breast cancer lines. ${ }^{21}$ Further studies may provide more information about the genes involved.

This study reports associations between chromosomal imbalances, histopathological parameters, overall survival rate and relapse rate in a homogeneous series of breast tumours. Previous CGH studies have considered only one to three pathological parameters, whereas 11 features were analysed in the present work.

The main associations described in our study concern $16 \mathrm{q}$ losses with features of good prognosis and 1q, 8q, $11 \mathrm{q}, 17 \mathrm{q}$ and $20 \mathrm{q}$ gains with poor prognosis (Table 4). $16 \mathrm{q}$ losses were significantly associated with no lymph node involvement, ER-positive expression and overexpression of bcl-2 (Table 4). Axillary lymph node status is the most important predictor of disease-free survival and overall survival in breast cancer, ${ }^{3}$ as we confirmed in our series $(P<0.001$, Table 3$)$. Our series showed that $52.9 \%$ of samples without node involvement have $16 \mathrm{q}$ losses versus only $11.1 \%$ in nodepositive cases $(P=0.025)$.

Oestrogen receptor and PR determinations are the main biological markers routinely used to address breast cancer therapy. ${ }^{22}$ In our series, ER and PR-positive patients showed a better overall survival and lower relapse rate than those with negative receptors. However, differences were not significant (i.e. ER-positive relapse rate was $19.6 \%$ compared with $43.3 \%$ in ERnegative tumours, $P=0.302$ ). A likely explanation could be the high overall survival of our series due to the fact that most of our patients belong to the Early Detection Programme developed in Navarra. The few number of events in each pathological subgroup could also explain this absence of significance. As previously reported, ${ }^{10}$ we detected $16 \mathrm{q}$ losses more frequently in ER-positive tumours than in ER-negative $(46.6 \%$ versus $11.9 \%, P<0.001)$, confirming its association with good prognosis. 


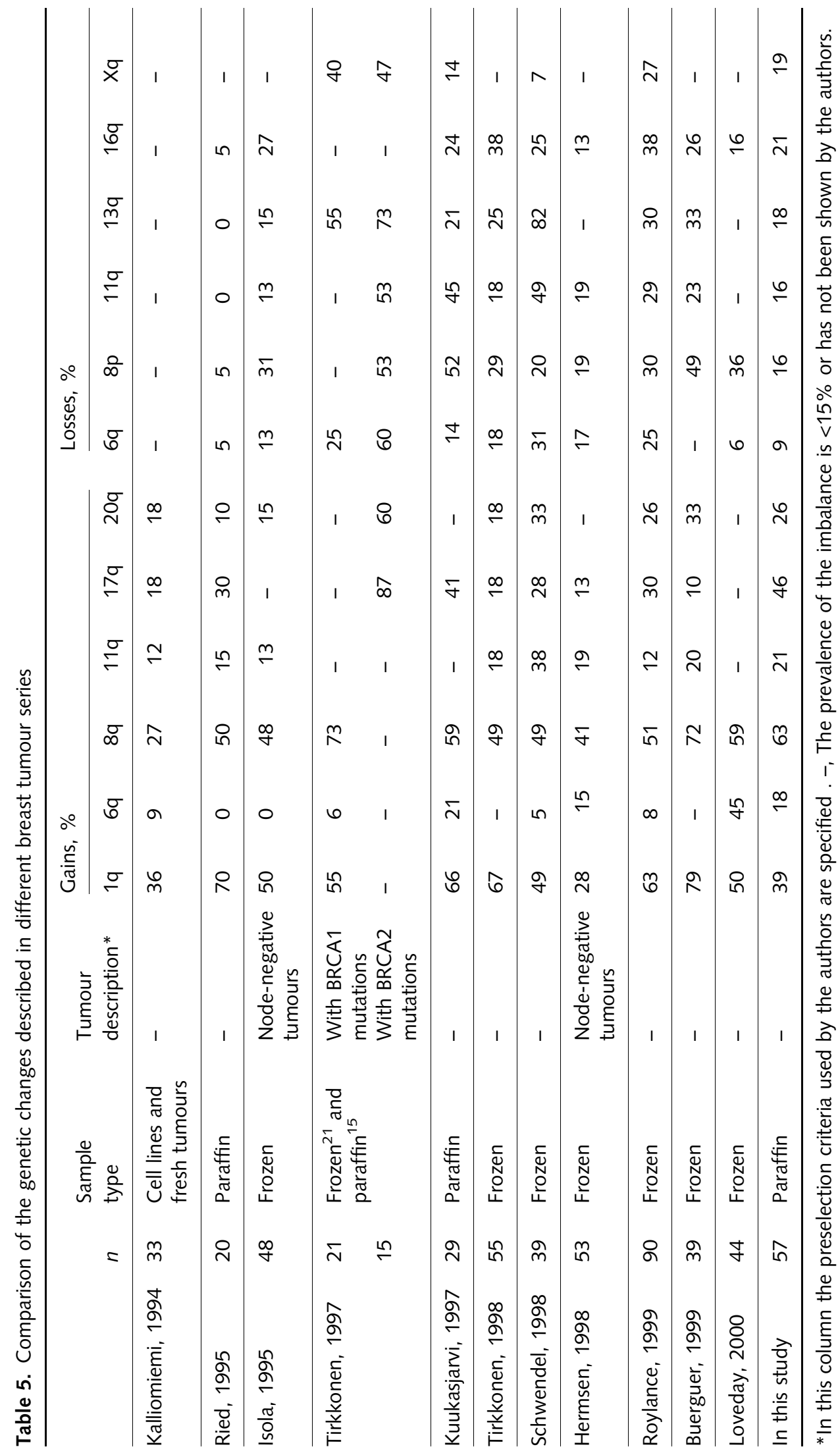


bcl-2 expression has been primarily considered as a predictive marker of response to adjuvant therapy. ${ }^{23}$ Most reports have also associated the lack of bcl-2 expression with poor survival. ${ }^{3,24}$ Previously to our study, bcl-2 expression has been included only once in CGH publications of breast cancer ${ }^{25}$ and it has never been associated with chromosomal imbalances. In our series, all tumours with bcl-2 over-expression showed $16 q$ losses $(P=0.014)$.

The association of $16 \mathrm{q}$ losses with other prognostic factors has previously shown the good prognostic value of this imbalance. Buerguer et al. found a lower frequency of $16 \mathrm{q}$ losses in invasive ductal breast carcinoma of grade III than in invasive ductal breast carcinoma of grade II and ductal in-situ carcinomas. ${ }^{9,26,27}$ They also associated this loss with the absence of necrosis and a significantly lower mitotic index and apoptotic index. We also found a higher frequency of $16 \mathrm{q}$ losses in grade II than grade III tumours $(66.7 \%$ versus $25 \%)$, but the differences were not significant because of the small size of the subgroups (eight tumours of grade II and three of grade III). Roylance et al. and Vos et al. found this aberration more frequently in well-differentiated tumours. ${ }^{8,28}$ Molecular genetic studies found a statistically significant association of LOH at 16q23.2-24.2 with absence of distant metastases, disease-free survival, and overall survival. ${ }^{29}$ Our study confirms these results and shows the association of $16 \mathrm{q}$ losses with two of the most important prognostic factors in breast cancer: node involvement and ER expression.

In our study, 1q, 8q, 11q, 17q and 20q gains were significantly associated with poor prognosis (Table 4). $8 \mathrm{q}$ gains were more frequent in tumours with poor clinical outcome (those with a high Nottingham Prognostic Index) than in those of the good prognosis group ( $81 \%$ versus $30 \%, P=0.022)$. These results are in agreement with several CGH studies where $8 \mathrm{q}$ gains were associated with a higher mitotic index, apoptotic index and mean nuclear area, ${ }^{6,11}$ poor prognosis in node-negative patients, ${ }^{7}$ high DNA index and S-phase fraction, ${ }^{5}$ grade III tumours, ${ }^{8}$ and aneuploidy. ${ }^{30}$ In our series, this aberration was also more frequent in aneuploid tumours $(66 \%)$ and node-positive tumours (64\%), although without statistical significance ( $P=0.290$ and $P=0.072$, respectively).

Our results also suggest that gains of $1 \mathrm{q}$ and $11 \mathrm{q}$ are associated with poor prognosis. The 5-year relapse rate was $41.3 \%$ for tumours with 1q gains versus $18 \%$ for tumours without this aberration $(P=0.063)$. Relapse rate was $50 \%$ for tumours with $11 \mathrm{q}$ gains compared with $23.7 \%$ for tumours without this imbalance $(P=0.063)$. We also found that $95 \%$ of tumours with $1 \mathrm{q}$ gains were $>20 \mathrm{~mm}(P=0.041)$. Other CGH publications have correlated 11q13 gains with more aggressive phenotypes such as hypodiploid tumours, ${ }^{31}$ intermediate and poorly differentiate tumours ${ }^{9}$ and poor prognosis. ${ }^{11}$ Consistent with these data, over-expression of genes located in this region (FGF3, FGF4 and cyclin D1) have been associated with a higher relapse rate in node-negative and ER-positive patients. ${ }^{32,33}$

The other associations described in Table 4 may be interpreted by caution because of the small size of the subgroups characterized.

Although no node involvement is the main feature of good prognosis in breast cancer, $30 \%$ of node-negative patients relapse within 10 years, and 30\% die because of the disease. ${ }^{34}$ The association that we have found between $17 \mathrm{q}$ gains and $20 \mathrm{q}$ gains with poor prognosis in node-negative patients could have clinical impact because it identifies a subgroup with poor prognosis $(P=0.039) .17 \mathrm{q}$ and $20 \mathrm{q}$ gains have been always associated with more aggressive phenotypes. ${ }^{4,28}$ Amplifications/over-expression of some genes located in these regions such as ERBB-2, Topoisomerase II $\alpha$ and AIB1 have been described as responsible for this poor outcome. ${ }^{35-37}$

In conclusion, we present a series of 57 formalinfixed paraffin-embedded breast tumours analysed by CGH. Successful results were obtained in $81.4 \%$ of the samples. Our results show that, with technical modifications, CGH in paraffin samples should be a useful tool for retrospective studies using archival material. These chromosomal imbalances could characterize new genetic markers of breast tumour progression. Together with conventional prognostic factors, losses on 16q and gains on 1q, 8q, 11q, 17q and 20q could help to identify new patient subgroups with a different clinical outcome. Further studies will be required to confirm the prognostic value of these aberrations in individual tumours and to identify the genes involved.

\section{Acknowledgements}

The authors thank Nekane Sanjosé and Minna Ahlstedt-Soinni for technical assistance. This work was supported by a grant of the Government of Navarra (634/1996) and the Asociación de Amigos of the University of Navarra.

\section{References}

1. Parkin DM, Pisani P, Ferlay J. Estimates of the worldwide incidence of 25 major cancers in 1990. Int. J. Cancer 1999; 80; $827-841$.

2. Bange J, Zwick E, Ullrich A. Molecular targets for breast cancer therapy and prevention. Nature Med. 2001; 7; 548-552. 
3. Fitzgibbons PL, Page DL, Weaver D et al. Prognostic factors in breast cancer. College of American Pathologists Consensus Statement 1999. Arch. Pathol. Lab. Med. 2000; 124; 966-978.

4. Tanner MM, Grenman S, Koul A et al. Frequent amplification of chromosomal region 20q12-q13 in ovarian cancer. Clin. Cancer Res. 2000; 6; 1833-1839.

5. Tirkkonen M, Tanner M, Karhu R, Kallioniemi A, Isola J, Kallioniemi OP. Molecular cytogenetics of primary breast cancer by CGH. Genes Chromosomes Cancer 1998; 21; 177-184.

6. Buerger H, Mommers E, Littman R et al. Correlation of morphologic and cytogenetic parameters of genetic instability with chromosomal alterations in in situ carcinomas of the breast. Am. J. Clin. Pathol. 2000; 114; 854-859.

7. Isola JJ, Kallioniemi OP, Chu LW et al. Genetic aberrations detected by comparative genomic hybridization predict outcome in nodenegative breast cancer. Am. J. Pathol. 1995; 147; 905-911.

8. Roylance R, Gorman P, Harris W et al. Comparative genomic hybridization of breast tumors stratified by histological grade reveals new insights into the biological progression of breast cancer. Cancer Res. 1999; 59; 1433-1436.

9. Buerger H, Otterbach F, Simon R et al. Different genetic pathways in the evolution of invasive breast cancer are associated with distinct morphological subtypes. J. Pathol. 1999; 189; 521-526.

10. Richard F, Pacyna-Gengelbach M, Schluns K et al. Patterns of chromosomal imbalances in invasive breast cancer. Int. J. Cancer 2000; 89; 305-310.

11. Hermsen MA, Baak JP, Meijer GA et al. Genetic analysis of 53 lymph node-negative breast carcinomas by $\mathrm{CGH}$ and relation to clinical, pathological, morphometric, and DNA cytometric prognostic factors. J. Pathol. 1998; 186; 356-362.

12. Sloane JP, Amendoeira I, Apostolikas N et al. Consistency achieved by 23 European pathologists from 12 countries in diagnosing breast disease and reporting prognostic features of carcinomas. European Commission Working Group on Breast Screening Pathology. Virchows Arch. 1999; 434; 3-10.

13. Isola J, DeVries S, Chu L, Ghazvini S, Waldman F. Analysis of changes in DNA sequence copy number by comparative genomic hybridization in archival paraffin-embedded tumor samples. Am. J. Pathol. 1994; 145; 1301-1308.

14. Kuukasjarvi T, Tanner M, Pennanen S, Karhu R, Visakorpi T, Isola J. Optimizing DOP-PCR for universal amplification of small DNA samples in comparative genomic hybridization. Genes Chromosomes Cancer 1997; 18; 94-101.

15. Persson K, Pandis N, Mertens F et al. Chromosomal aberrations in breast cancer: a comparison between cytogenetics and comparative genomic hybridization. Genes Chromosomes Cancer 1999; 25; 115-122.

16. Schwendel A, Richard F, Langreck $\mathrm{H}$ et al. Chromosome alterations in breast carcinomas: frequent involvement of DNA losses including chromosomes 4q and 21q. Br. J. Cancer 1998; 78; 806-811.

17. Loveday RL, Greenman J, Simcox DL et al. Genetic changes in breast cancer detected by comparative genomic hybridisation. Int. J. Cancer 2000; 86; 494-500.

18. Kuukasjarvi T, Karhu R, Tanner M et al. Genetic heterogeneity and clonal evolution underlying development of asynchronous metastasis in human breast cancer. Cancer Res. 1997; 57; 1597-1604.

19. Rodriguez C, Causse A, Ursule E, Theillet C. At least five regions of imbalance on $6 \mathrm{q}$ in breast tumors, combining losses and gains. Genes Chromosomes Cancer 2000; 27; 76-84.

20. Kauraniemi P, Hedenfalk I, Persson K et al. MYB oncogene amplification in hereditary BRCA1 breast cancer. Cancer Res. 2000; 60; 5323-5328.
21. Forozan F, Mahlamaki EH, Monni O et al. Comparative genomic hybridization analysis of 38 breast cancer cell lines: a basis for interpreting complementary DNA microarray data. Cancer Res. 2000; 60; 4519-4525.

22. Lindblom A, Liljegren A. Regular review: tumour markers in malignancies. BMJ 2000; 320; 424-427.

23. Ciocca DR, Elledge R. Molecular markers for predicting response to tamoxifen in breast cancer patients. Endocrine 2000; 13; 1-10.

24. Le MG, Mathieu MC, Douc-Rasy S et al. c-myc, p53 and bcl-2, apoptosis-related genes in infiltrating breast carcinomas: evidence of a link between bcl-2 protein over-expression and a lower risk of metastasis and death in operable patients. Int. J. Cancer 1999; 84; 562-567.

25. Jones C, Damiani S, Wells D, Chaggar R, Lakhani SR, Eusebi V. Molecular cytogenetic comparison of apocrine hyperplasia and apocrine carcinoma of the breast. Am. J. Pathol. 2001; $158 ; 207-214$.

26. Buerger H, Mommers E, Littman $\mathrm{R}$ et al. Ductal invasive G2 and G3 carcinomas of the breast are the end stages of at least two different lines of genetic evolution. J. Pathol. 2001; 194; 165-170.

27. Roylance R, Gorman P, Hanby A, Tomlinson I. Allelic imbalance analysis of chromosome 16q shows that grade I and grade III invasive ductal breast cancers follow different genetic pathways. J. Pathol. 2002; 196; 32-36.

28. Vos CB, ter Haar NT, Rosenberg C et al. Genetic alterations on chromosome 16 and 17 are important features of ductal carcinoma in situ of the breast and are associated with histologic type. Br. J. Cancer 1999; 81; 1410-1418.

29. Hansen LL, Yilmaz M, Overgaard J, Andersen J, Kruse TA. Allelic loss of 16q23.2-24.2 is an independent marker of good prognosis in primary breast cancer. Cancer Res. 1998; 58; 2166-2169.

30. Ried T, Just KE, Holtgreve-Grez $\mathrm{H}$ et al. Comparative genomic hybridization of formalin-fixed, paraffin-embedded breast tumors reveals different patterns of chromosomal gains and losses in fibroadenomas and diploid and aneuploid carcinomas. Cancer Res. 1995; 55; 5415-5423.

31. Tanner MM, Karhu RA, Nupponen NN et al. Genetic aberrations in hypodiploid breast cancer: frequent loss of chromosome 4 and amplification of cyclin D1 oncogene. Am. J. Pathol. 1998; 153; 191-199.

32. Jaakkola S, Salmikangas P, Nylund S et al. Amplification of fgfr4 gene in human breast and gynecological cancers. Int. J. Cancer 1993; 54; 378-382.

33. Barnes DM, Gillett CE. Cyclin D1 in breast cancer. Breast Cancer Res. Treat. 1998; 52; 1-15.

34. Reed W, Hannisdal E, Boehler PJ, Gundersen S, Host H, Marthin J. The prognostic value of p53 and c-erb B-2 immunostaining is overrated for patients with lymph node negative breast carcinoma: a multivariate analysis of prognostic factors in 613 patients with a follow-up of 14-30 years. Cancer 2000; 88; 804-813.

35. Hanna W, Kahn HJ, Trudeau M. Evaluation of HER-2/neu (erbB2) status in breast cancer: from bench to bedside. Mod. Pathol. 1999; 12; 827-834.

36. Jarvinen TA, Holli K, Kuukasjarvi T, Isola JJ. Predictive value of topoisomerase IIalpha and other prognostic factors for epirubicin chemotherapy in advanced breast cancer. Br. J. Cancer 1998; 77; 2267-2273.

37. Bouras T, Southey MC, Venter DJ. Overexpression of the steroid receptor coactivator AIB1 in breast cancer correlates with the absence of estrogen and progesterone receptors and positivity for p53 and HER2/neu. Cancer Res. 2001; 61; 903-907. 